\title{
Compressibility of $\mathrm{AgI}-\mathrm{Ag}_{2} \mathrm{MoO}_{4}$ System Measured in Wide Range of Composition
}

\author{
Z. WiŚnIEWSKI, R. WiśniEWSKI AND T. WiLCZYŃSKA \\ Institute of Atomic Energy 05-400 Otwock-Swierk, Poland
}

\begin{abstract}
Results of compressibility measurements of $\mathrm{AgI}-\mathrm{Ag}_{2} \mathrm{MoO}_{4}$ materials for different concentrations of AgI were presented. The obtained results were compared with phase diagram and internal structure of material. It was found that observed values of compressibility coefficient can be related to internal structure of investigated material.
\end{abstract}

PACS numbers: 61.43.Er, 61.66.Dk, 62.50.-p

\section{Introduction}

Materials belonging to group $\mathrm{AgI}-\mathrm{Ag}_{2} \mathrm{MoO}_{4}$ are classified as ionic conductors. They found application in medicine, electronics, and sensors construction. The most frequent way of fabricating $\mathrm{AgI}-\mathrm{Ag}_{2} \mathrm{MoO}_{4}$ material is rapid quenching of liquid [1-5]. In this way one can obtain materials of different internal structures [4]. They can appear both as composites with crystalline precipitates and amorphous ones with homogeneous structures. In the second case they are referred to as ionic conducting oxide glasses $[2,3,5]$. Ionic conducting oxide are extensively investigated, while properties of composites with crystalline precipitates are much less known. In case of $\mathrm{AgI}-\mathrm{Ag}_{2} \mathrm{MoO}_{4}$, however situation is slightly different. Because of relative easiness of synthesis and medical application some works concerning also non-homogeneous materials exists. Even phase diagram was found [4].

\section{Experiment}

For obtaining materials as starting materials AgI, $\mathrm{Ag}_{2} \mathrm{O}$ and $\mathrm{MoO}_{3}$, provided by Sigma Aldrich, were used. This materials were placed in ceramic crucibles then heated in pipe heater in temperature up to $800^{\circ} \mathrm{C}$ until complete melting took place. Then obtained liquid was poured between two metal plates. Chemical composition was checked by X-ray photoelectron spectroscopy (XPS) method and by mass control. For compressibility measurements tensometric technique was used.

Details of this method are given in [6,7], so here only the main principle will be given. On the surface of a sample a special device called tensometer is glued. This device consists of two foil layers; one of them is conducting. The conducting foil called grid is connected to external resistance meter. The sample with tensometer is than enclosed in pressure vessel and exposed to hydrostatic pressure. As a result of hydrostatic pressure the volume of a sample decreases, this in turn changes dimensions of grid. Changes of grid dimensions affects its electric resistance. Therefore, by observing changes of grid resistance one can obtain information about pressure induced change of the sample volume. Knowing pressure induced change of volume one can count compressibility coefficient $a$ defined by formula:

$$
\frac{\Delta V}{V_{0}}=-a p,
$$

where $p$ is hydrostatic pressure, $\Delta V-$ pressure induced change of volume, $V_{0}$ - volume at normal pressure (0.1 MPa).

Main advantage of this method is that it can be applied both to amorphous and crystalline bodies. Additional advantage is that it measures volume changes of the whole sample, not only changes of elementary cell, so it can be useful in compressibility coefficient of porous or amorphous bodies.

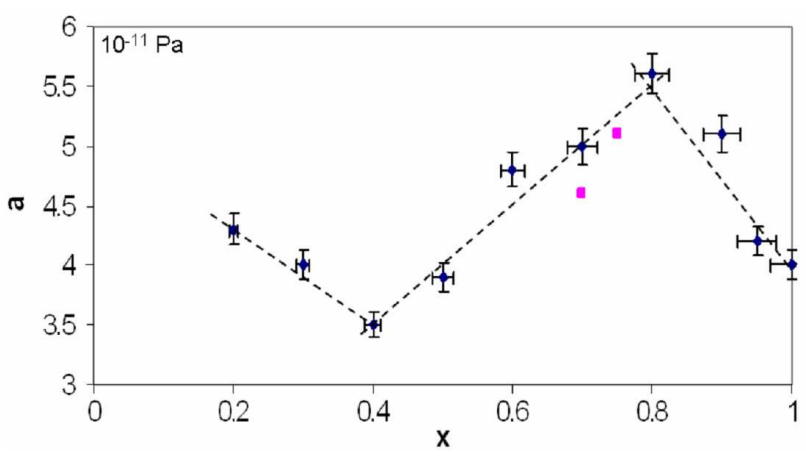

Fig. 1. Compressibility coefficients of $\mathrm{AgI}-\mathrm{Ag}_{2} \mathrm{MoO}_{4}$. Straight lines are guide for eyes.

\section{Results}

Compressibility coefficients for $\mathrm{AgI}-\mathrm{Ag}_{2} \mathrm{MoO}_{4}$ obtained by tensometric method are presented in Fig. 1. For 
enabling comparison between materials parameter $x$ was introduced which reflects amount of silver iodide present in samples. As a result every sample can be described by a formula $x \mathrm{AgI}-(1-x)\left(\mathrm{Ag}_{2} \mathrm{MoO}_{4}\right)$. Consequently samples with different amount of AgI have different $x$. One can see (Fig. 1) that three different areas can be distinguished. In a first region where concentration of $\mathrm{AgI}$ is relatively small, the value of compressibility coefficient decreases with $x$. In a second region value of compressibility coefficient increases with AgI content and in the last one again decreases. Such complicated dependence can be understood on the background of previous results $[4,8]$. By comparison with phase diagram for $x$ AgI- $(1-x)\left(\mathrm{Ag}_{2} \mathrm{MoO}_{4}\right)$ shows that different regions represent different kinds of structures. Materials for which $x<0.4$ are composites with complicated structure. It consists of two phases, an amorphous one and crystalline precipitates of $\mathrm{Ag}_{2} \mathrm{MoO}_{4}$. Characteristic feature of this structure is presence of numerous empty spaces, which constitute additional free volume. This additional free volume increases compressibility of material. Amount of its free volume decreases with AgI content so value of compressibility coefficient also decreases. For materials with $x>0.4$ the structure of material is different, so the dependence of compressibility is different. In case of amorphous structures value of compressibility coefficient increases with AgI content. The third type of structure appears for materials for witch $x>0.8$. In this case the material is a two-phase composite composed of amorphous phase and $\beta$-AgI. Observed values of compressibility coefficients are weighted averages of amorphous and crystalline phases.

\section{Conclusion}

Compressibility of $\mathrm{AgI}-\mathrm{Ag}_{2} \mathrm{MoO}_{4}$ materials with different concentration of AgI was studied by tensometric method. It was found that three regions can be distinguished. In each of this region changes of compressibility coefficient have different character. In the first region where samples have precipitates the value of compressibility coefficient decreases with pressure.

In the second region where materials have homogeneous and amorphous structure, the value of compressibility coefficient increases with AgI content. And in the third region value of compressibility coefficients once again decreases with AgI content.

\section{References}

[1] T. Minami, K. Imazawa, M. Tanaka, J. Non-Cryst. Solids 42469 (1980).

[2] J.M. Hutchinson, M.D. Ingram, A.H.J. Robertson, Philos. Mag. B 66449 (1992).

[3] Y. Oyama, J. Kawamura, Solid State Ionics 53-56, 1221 (1992).

[4] P. Mustarell, C. Tomasi, E. Quartarone, A. Magistris, Rhys. Rev B 58, 9054 (1998).

[5] N. Machida, H. Eckert, Solid State Ionics 105, 255 (1998).

[6] Z. Wiśniewski, R. Wiśniewski, J.L. Nowiński, Rev. Sci. Instrum. 72, 2829 (2001).

[7] Z. Wiśniewski, R. Wiśniewski, J.L. Nowiński, Solid State Ionics 157, 275 (2003).

[8] Z. Wiśniewski, L. Górski, D. Zasada, Acta Phys. Pol. A 113, 1231 (2008). 